Revista Bioética

\title{
ATUALIZAÇÃO
}

\section{Perspectivas bioéticas sobre tomada de decisão em tempos de pandemia}

Mário Antônio Sanches ${ }^{1}$, Thiago Rocha da Cunha ${ }^{1}$, Sergio Surugi de Siqueira ${ }^{1}$, José Eduardo de Siqueira ${ }^{2}$

1. Programa de Pós-Graduação em Bioética, Universidade Católica do Paraná, Curitiba/PR, Brasil. 2. Programa de Pós-Graduação em Bioética, Universidade Católica do Paraná, Londrina/PR, Brasil.

\section{Resumo}

Este artigo busca identificar contribuições da bioética para enfrentar conflitos relacionados à tomada de decisão em tempos de pandemia. Trata-se de texto elaborado a partir de reflexões pessoais dos autores em diálogo com a literatura de diferentes perspectivas da bioética. Com fundamento em relatos históricos, argumenta-se que, durante epidemias, a sociedade passa a atuar em modo de excepcionalidade, o que exige argumentação mais apurada para se posicionar ante os conflitos que surgem. Analisam-se então diferentes vertentes teóricas - principialismo, personalismo, utilitarismo e bioética social -, recolhendo de cada uma elementos que podem nortear a tomada de decisão. Com base nessas contribuições, propõem-se parâmetros para a atuação dos profissionais da saúde, reconhecendo igual valor em cada vida humana, com o propósito de salvar o maior número de pessoas possível. Por fim, aponta-se para a responsabilidade de agentes políticos.

Palavras-chave: Pandemias. Bioética. Justiça. Pessoalidade.

\section{Resumen}

\section{Perspectivas bioéticas sobre la toma de decisiones en tiempos de pandemia}

Este artículo tiene como objetivo identificar la contribución de la bioética para hacer frente a los conflictos relacionados con la toma de decisiones en tiempos de pandemia. Se trata de un texto elaborado con base en las reflexiones personales de los autores en diálogo con la literatura de diferentes perspectivas de la bioética. Con base en los relatos históricos, se argumenta que, durante epidemias, la sociedad pasa a actuar en modo de excepcionalidad, lo que requiere una argumentación más precisa para posicionarse ante los conflictos que surgen. Se analizan entonces diferentes vertientes teóricas - el principialismo, el personalismo, el utilitarismo y la bioética social -, recogiendo de cada una los elementos que pueden orientar la toma de decisiones. Con base en dichas contribuciones, se proponen parámetros para la actuación de los profesionales de la salud, reconociendo el mismo valor en cada vida humana, con el propósito de salvar al mayor número posible de personas. Por fin, se apunta hacia la responsabilidad de los agentes políticos.

Palabras clave: Pandemias. Bioética. Justicia. Personeidad.

\begin{abstract}
Bioethical perspectives on decision-making in times of pandemic

This article aims to identify the contribution of bioethics to resolve decision-making conflicts in healthcare in times of pandemic. The research was based on the authors' personal reflections in a dialogue with the literature and different bioethical perspectives. Historical accounts show that when a society is experiencing an epidemic it starts to function in a mode of social exceptionality, reinforcing the need for a more appropriate form of reasoning before the ethical conflicts that may arise from this situation. Some approaches to bioethics - principlism, personalism, utilitarianism and social bioethics - are briefly examined in order to obtain the elements for guiding the decisionmaking process. Finally, we suggest some parameters for health professionals, recognizing the value of all human lives, to save as many lives as possible.
\end{abstract}

Keywords: Pandemics. Bioethics. Justice. Personhood.

Declaram não haver conflito de interesse. 
Em tempos de pandemia, profissionais de saúde devem tomar decisões complexas, como escolher quem será conduzido a tratamento com potencial de cura, sabendo que os pacientes excluídos estão sendo praticamente deixados à morte. Diante dessa situação angustiante, buscam-se com afinco referenciais teóricos e técnicos que possam estabelecer critérios para a tomada de decisão. A reflexão exige análise rigorosa dos argumentos, franqueza e honestidade, para evitar que o debate se torne interminável e nada se concretize. Este ensaio questiona se as atuais perspectivas do campo da bioética são efetivas em meio a esse cenário.

Este texto tentará responder à seguinte pergunta: que vertente da bioética pode amparar os melhores argumentos éticos para enfrentar os conflitos gerados pela pandemia? Isso implica diversas outras indagações, como: é razoável privilegiar pacientes jovens em detrimento dos mais velhos, considerando que a morbimortalidade é maior entre idosos? É prudente subestimar este grupo, ainda que o ordenamento jurídico do país estabeleça orientação diametralmente oposta? Profissionais de saúde cometem infração ética e incorrem em crime de omissão de socorro ao deixar de oferecer assistência adequada para pessoas vulneráveis? A busca de resposta para tais questões não se esgota no campo da bioética, mas este artigo pretende seguir algumas pistas, mantendo-se aberto à necessidade de aprofundamento futuro. De início, apresenta-se brevemente a pandemia que motiva a reflexão.

Em meados de dezembro de 2019 foram identificados na China vários casos de doença respiratória de origem desconhecida, que se caracterizava por tosse seca, febre, fadiga e, com menos frequência, sintomas gastrointestinais. Inicialmente, a enfermidade acometeu $66 \%$ das pessoas que trabalhavam na venda de pescados do "mercado molhado" de Wuhan, cidade da província de Hubei ${ }^{1}$. No dia 31 daquele mês, a Organização Mundial da Saúde (OMS) foi oficialmente informada sobre o surto de casos de pneumonia de causa desconhecida concentrados na região, e já no dia seguinte o mercado foi fechado pelas autoridades chinesas.

Mais tarde, o agente etiológico foi identificado como novo betacoronavírus, que inicialmente recebeu o nome de 2019-nCoV e depois foi renomeado como Sars-CoV-2, causador da doença cuja nomenclatura oficial se tornou "covid-19". Com a disseminação da enfermidade para outros países, em 30 de janeiro de 2020 a OMS declarou emergência em saúde com abrangência internacional, mas somente no dia 11 de março a pandemia foi oficialmente declarada, com milhões de casos reportados e centenas de milhares de mortes ${ }^{2}$.
Este ensaio será elaborado a partir de reflexões pessoais e do diálogo com autores de diversas áreas, lançando mão de referenciais teóricos para contribuir com o debate. Trata-se de trabalho elaborado sob o impacto da pandemia e que não espera atuar em campo de fácil consenso.

\section{Sociedades em tempos de pandemia}

Registrando a Peste de Atenas, ocorrida em 430 a.C., Tucídides ${ }^{3}$ afirma que a epidemia se deu em contexto de desorganização social e moral. Dessa afirmação pode-se entender que a causa da peste seria a degradação moral, ou que a sociedade entra em modo de excepcionalidade pois sua imoralidade é exacerbada pela doença ${ }^{3}$.

Um primeiro aspecto dessa excepcionalidade é a ineficiência dos meios usuais de tratamento. Nesse sentido, o relato da Peste de Atenas ecoa toda vez que a sociedade vivencia nova epidemia: Nada podiam fazer os médicos por seu desconhecimento da enfermidade que tratavam pela primeira vez ${ }^{4}$. É como se Tucídides estivesse narrando a pandemia de covid-19 ao apontar que os profissionais de saúde (como diríamos hoje) eram os principais afetados porque eram os que mais se aproximavam dos enfermos ${ }^{4}$.

A imagem mais dramática de Tucídides é a dos corpos insepultos em Atenas, o que fugia de todos os padrões de normalidade da cultura grega, dada a obrigação sagrada de sepultar adequadamente os mortos. Semelhantemente, Galeno - médico grego que estava em Roma e presenciou a Primeira Peste Antonina (165-170 d.C.), classificando-a, segundo Gozalbes Cravioto e García García, como enfermidade grave, frequentemente mortal e que atuava sobre um grande número de pessoas ${ }^{5}$ - recomendava que os funerais não fossem realizados dentro dos limites da cidade, como era costume na época.

Nesses períodos angustiantes, as relações entre as pessoas se alteram, para espanto de Boccaccio, que vivenciou a Peste Negra (1348-1350): Os pais e as mães sentiam repugnância de visitar e de servir os filhos, como se estes não fossem seus (e esta é a pior coisa, quase inacreditável) ${ }^{6}$. Outra passagem dramática é encontrada na obra de Muratori, que relata a peste na Espanha, no início do século XVIII: Às mulheres que amamentam é necessário tirar-lhes os filhos imediatamente após o início do mal, buscando depois cãezinhos para chupar o leite quando necessário ${ }^{7}$.

Registros mais recentes, no campo da ficção, são duas obras que descrevem dramas semelhantes ao da atual pandemia. Em 1947, Albert Camus publica 
$A_{\text {peste }}^{8}$, no qual reflete sobre o absurdo da existência humana, considerando a simultaneidade do mal e da solidariedade na luta contra epidemia que testa os limites morais dos habitantes da cidade de Oran. Já Ensaio sobre a cegueira ${ }^{9}$, do escritor português José Saramago, descreve a "cegueira branca" que se propaga de maneira incontrolada entre a população de parte não especificada do planeta. Trata-se de parábola sobre a cegueira moral em tempos de enfermidade promovida por agente desconhecido, em tudo semelhante à atual pandemia, em meio à qual, apesar dos significativos avanços da ciência, continuamos "cegos". Nossa esperança é a de que a atual "peste" seja transitória, como a descrita por Saramago.

Esses fragmentos visam apenas apontar que muitas situações vivenciadas na atual pandemia são recorrentes. As cenas testemunhadas chocam, como as inacreditáveis imagens de sepultamentos em valas comuns ou de caminhões enfileirados para buscar cadáveres que serão enterrados apressadamente, sem a devida cerimônia. Nota-se, portanto, o assombro recorrente diante das epidemias, quando normas e regras se revelam inócuas e impõem a todos condições excepcionais.

0 argumento inicial deste artigo é o de que, em meio a pandemia, a sociedade passa a atuar em modo de excepcionalidade, e medidas políticas e comportamentos sociais que jamais seriam aceitos fora desse contexto passam a ser defendidos abertamente. No cuidado da saúde, é como se as situações de emergência, raras e concentradas em determinados serviços, subitamente se tornassem a regra.

Colhido de experiências epidêmicas passadas, este argumento precisa ser destacado, pois não se pode ter receio de aplicar medidas de emergência em situações que as exigem, assim como é preciso recusá-las caso o contexto se altere. Esta é postura própria da bioética, compreendida como campo do conhecimento que visa fornecer orientações práticas para um agir contextualizado. Esse posicionamento encontra eco em muitas perspectivas tradicionais que compreendem a ação moral como ação em contexto.

Na sequência, introduzem-se possíveis contribuições das principais tendências da bioética para a tomada de decisão em tempos de conflitos morais. Buscam-se respostas principalmente no principialismo, personalismo, utilitarismo e na bioética social. Antes, porém, é necessário apresentar rapidamente a noção de conflitos nesse campo do conhecimento.

Por se pautar pela valorização da diversidade interdisciplinaridade, interculturalidade e diversidade moral -, a bioética não busca delimitar respostas certas para a ação humana. O que ela pretende é apontar situações de conflito em que se pode chegar a alternativas razoáveis e prudentes após debate aberto e diverso. Desse modo, afastam-se da bioética todos aqueles que se apregoam portadores de verdade única. Abre-se espaço para quem defende que a verdade pode ser alcançada, ou ao menos vislumbrada, a partir de busca coletiva. Quando nascem do consenso, as ações não geram conflitos. Os problemas surgem quando os atores discordam sobre o curso a ser seguido, ou quando a ação sugerida agride valores e convicções dos envolvidos.

\section{Princípios que marcam a bioética}

Quem começa a estudar bioética logo se depara com quatro preceitos amplamente divulgados - beneficência, não maleficência, autonomia e justiça -, propostos por Beauchamp e Childress ${ }^{10} \mathrm{em}$ 1979 na obra Princípios de ética biomédica, que se tornaria a principal referência da vertente "principialista". O propósito dessa tendência era recolher da tradição religiosa e filosófica preceitos universais a serem aplicados na solução de conflitos éticos surgidos na prática biomédica.

Os princípios indicados por Beauchamp e Childress ${ }^{10}$ têm fundamentação histórica. A beneficência, por exemplo, é característica marcante da ética médica iniciada por Hipócrates na Grécia Antiga. O surgimento da bioética promoveu o debate acerca dos dilemas éticos em saúde, ajudando a identificar problemas e buscar soluções. Porém, com o tempo, o principialismo - tendência que partiu dos Estados Unidos e se tornou dominante - passou a ser criticado por seu pragmatismo e por suas conclusões pretensamente universais.

No contexto de "excepcionalidade social" das pandemias, a aplicação dos quatro princípios depende ainda mais das virtudes e da capacidade de discernimento dos atores. Essa dependência "flexibiliza" esses preceitos, que não podem ser aplicados de maneira cega e independente do contexto. Não se pode, portanto, considerá-los a partir de perspectiva fechada. A autonomia, por exemplo, deve ser privilegiada, contanto que não prejudique outras pessoas.

O princípio da justiça limita a autonomia, como quando se obriga as pessoas ao confinamento ou isolamento social, impedindo o direito consagrado de ir e vir. Esse conflito também se apresenta nas intervenções experimentais que envolvem seres humanos, necessárias para descobrir instrumentos que possam trazer de volta a normalidade. Nesses casos, o consentimento 
informado, expressão maior da autonomia, pode ser até dispensado quando a relevância social das respostas potenciais de um estudo for maior do que os danos ao direito individual.

Em cenário de sobrecarga dos recursos sanitários, não é raro que profissionais tenham que decidir quem será privado do tratamento ideal. A urgência em decidir causa angústia, e muitas vezes deve-se agir sem poder apreciar mais profundamente as circunstâncias. Para diminuir tal carga, é comum que se clame por protocolos oficiais - um engano, pois "algoritmos éticos" não são capazes de impedir conflitos e, por vezes, levam a intervenções impertinentes ou mesmo injustas.

A virtude de avaliar profundamente a situação e balancear beneficência com danos potenciais e respeito à autonomia com justiça é qualidade fundamental em emergências. Ao final, as decisões deverão sempre se basear nessa avaliação. $A$ complexidade das circunstâncias não permite olhar superficial, e nesses momentos o conhecimento técnico deve ser instrumentalizado para influenciar o discernimento. Assim, a bioética principialista estará presente em qualquer decisão em saúde, ainda que se mostre insuficiente em muitos casos.

\section{Todos com igual dignidade: como escolher?}

Outra vertente importante da bioética é o personalismo ${ }^{11}$, que parte de bases do cristianismo pontualmente relacionadas a campos específicos da saúde humana e da pesquisa científica. Por seu fundamento religioso, nem sempre o personalismo é bem acolhido. Todavia, essa visão coincide com a leitura de mundo de boa parte dos profissionais de saúde, criados em sociedades de forte herança cristã. Observa-se, assim, que essa vertente traz perspectiva bastante razoável para o conflito aqui analisado.

A reflexão que surge dessa tradição traz à tona percepção elevada do ser humano. 0 termo "pessoa" tem diversas conotações em bioética, mas no personalismo seu significado é indiscutivel: cada ser humano - no percurso de sua existência, do embrião à velhice -, por ser chamado à existência como imagem e semelhança de Deus, é considerado pessoa, e essa condição não é enriquecida nem empobrecida por vicissitudes sociais e históricas.

Esta compreensão de ser humano implica a afirmação e defesa da dignidade individual, que não é conquistada nem sofre gradação. Assim, a vida de alguém não pode ser negligenciada, relativizada ou depreciada por outra pessoa ou pela coletividade.
Todavia, segundo essa vertente, a vida pode ser doada, ofertada, ou sacrificada pelo próprio indivíduo sempre que a situação exigir a defesa de valores tão nobres quanto a própria vida ou ainda mais elevados. Não se justifica o apego intransigente e obstinado à transitoriedade da vida na Terra, visto que é no Eterno que ela se fundamenta. Esses são os pressupostos do personalismo para a assistência em saúde.

Nesse enfoque, a afirmação da dignidade não é compreendida como defesa do individualismo, pois se destacam as dimensões sociais e relacionais da pessoa, de modo a se exigir, coerentemente, a defesa da dignidade do outro. Assim, é estabelecido o compromisso pessoal com a sociedade, que pode levar a sacrifícios voluntariamente assumidos para acolher e ajudar os mais necessitados.

Para o personalismo, o paciente pode legitimamente renunciar a cuidados que apenas prolongariam dolorosamente a própria existência. Caso a pessoa não tenha condições de exercer sua autonomia, outros - como familiares e profissionais de saúde também podem limitar tais cuidados, desde que os procedimentos a que se está renunciando sejam inócuos, sem efetividade terapêutica, e somente prolonguem a agonia. Decisões como essa são amparadas por várias vertentes da bioética.

No entanto, o personalismo apresenta limites para a tomada de decisão em tempos de pandemia, pois as terapêuticas - uso de respirador, por exemplo - não são inócuas, e as possibilidades de cura da doença são significativas. Como escolher qual paciente deve ser tratado? Por vezes, noticia-se que um paciente renuncia conscientemente ao tratamento em prol de outro. Esse é gesto nobre, acolhido pela perspectiva personalista. Mas, à parte dessa postura incomum, o que fazer?

O personalismo pode apenas dizer ao profissional de saúde que a vida de todo ser humano tem igual dignidade e apreço, então se deve salvar o maior número possível de pessoas. Mas quando as condições concretas não possibilitam salvar a todos, essa vertente pode apenas lamentar as perdas, sem tratá-las como problema ético ou responsabilidade dos envolvidos. Nessa perspectiva, a responsabilidade moral só se aplica quando se pode agir livre e conscientemente.

Pode-se ilustrar os limites do personalismo com um exemplo: uma creche pega fogo e alguém entra para salvar as crianças. Essa pessoa, no entanto, salva apenas aqueles que estão mais próximos da porta e podem ser alcançados mais facilmente. Um personalista aceitaria o seguinte raciocínio: a opção do agente era salvar a todos, e ele fez 
o máximo que pôde. Todavia, essa perspectiva não aceitaria tal ação caso o critério do agente fosse salvar as pessoas cuja vida julga mais valiosas.

\section{Utilitarismo: o maior bem para o maior número}

O utilitarismo é corrente ética desenvolvida no final do século XVIII pelo filósofo inglês Jeremy Bentham ${ }^{12}$. Trata-se de abordagem consequencialista que se opõe às éticas principialistas ou deontológicas, propondo a validação ou recusa das decisões a partir da avaliação de suas consequências, e não dos motivos, valores ou deveres que as precedem. Em geral, para que seja considerada correta, a ação utilitarista deve resultar de cálculo que maximize a felicidade e minimize a infelicidade, de modo que a primeira seja sempre maior do que a segunda.

Uma das grandes críticas ao utilitarismo diz respeito à definição do que seria "felicidade", ou seja, o bem a ser maximizado. Bentham ${ }^{12}$, seguindo linha hedonista, indicou inicialmente que a felicidade seria o "prazer" que os corpos dos agentes envolvidos podem experienciar, enquanto a "dor" indicaria o mal a ser minimizado. $\mathrm{O}$ autor chegou a propor marcadores quantitativos para mensurar o prazer em termos de intensidade, duração, certeza, proximidade, fecundidade e pureza. Já seu discípulo, John Stuart Mill ${ }^{13}$, definiu a felicidade em termos qualitativos, estabelecendo critérios subjetivamente qualificados que se sobreporiam a meras sensações físicas - busca pelo amor e pela beleza, tranquilidade física e emocional, prazer intelectual, de cultivar boas relações e amizades etc.

Desde então o utilitarismo vem sendo adotado e desenvolvido por diversos autores. Na bioética, especialmente nas últimas décadas, essa perspectiva ganhou espaço importante. Por exemplo, é aplicada nas discussões sobre direitos dos animais, quando se argumenta que o prazer e a dor (ou interesses) de todos os seres sencientes devem ser levados em consideração no cálculo utilitário, assim como nas discussões sobre ética em saúde pública, particularmente nas considerações sobre alocação de recursos limitados ${ }^{14}$. Nesses casos, o princípio utilitarista aponta que o correto é priorizar os recursos que proporcionam mais saúde ao maior número de pessoas durante o maior tempo possível.

Fortes ${ }^{14}$ aponta exemplos corriqueiros de aplicação do cálculo utilitário na saúde pública, como a vacinação em massa em detrimento de abordagens que focam apenas dimensões curativas, na medida em que essas últimas são menos eficientes e mais custosas. Todavia, mesmo no contexto da bioética o utilitarismo encontra resistência. Critica-se, por exemplo, o foco na eficiência, que implica decisões que considerem o maior benefício com o menor custo, possibilitando que a assistência seja submetida à lógica economicista, centrada na redução de gastos para os sistemas públicos ou privados ${ }^{15}$.

No contexto das orientações clínicas em situações excepcionais, como no caso da alocação de ventilação mecânica em unidades de terapia intensiva durante a pandemia de covid-19, a abordagem utilitarista tem sido a resposta-padrão em muitos países. É ela que serve de base à priorização de jovens e adultos em detrimento de pessoas mais velhas. Segundo o cálculo utilitário, idosos teriam menos tempo de vida e, portanto, menor possibilidade de desfrutar o prazer, a saúde ou a felicidade ${ }^{16}$. Essas orientações, no entanto, vieram acompanhadas de muitas críticas, uma vez que implicam formas inadmissíveis de discriminação etária, que é violação inaceitável da dignidade e dos direitos humanos.

\section{Bioética social: priorização de grupos vulneráveis}

Compreende-se aqui "bioética social" como aquela produzida na América Latina a partir dos anos 1990, quando bioeticistas da região passam a identificar as limitações das teorias criadas em países desenvolvidos, que não responderiam aos conflitos éticos locais. Essas limitações ocorriam pela incapacidade da bioética estadunidense e europeia de ir além de contextos puramente clínicos e hospitalares, quase sempre focando a autonomia do paciente e a beneficência pela perspectiva do profissional. Até então, desconsideravam-se temas relacionados à vulnerabilidade socioeconômica, como falta de acesso à saúde, exclusão social, fome e violência, entre outras questões que ainda hoje impactam diretamente a vida e a saúde da maior parte da população da América Latina e do Caribe.

Autores como Márcio Fabri dos Anjos ${ }^{17}$, Volnei Garrafa ${ }^{18}$ e Fermin Roland Schramm ${ }^{19}$ passaram a incluir a dimensão social nas reflexões sobre bioética. Ao longo dos anos, a vertente foi se desenvolvendo com a contribuição de outros autores, de outras regiões e áreas do conhecimento. A despeito de diferenças pontuais, comuns em um campo interdisciplinar em construção, o que define a bioética social latino-americana é perspectiva politizada, crítica e contextualizada sobre os conflitos éticos envolvendo a saúde, compreendida em suas dimensões individual, coletiva e global. 
A principal contribuição da bioética social no contexto da covid-19 é a priorização de grupos socialmente fragilizados. Nessa perspectiva, a intervenção deve favorecer os mais excluídos, marginalizados e vulnerabilizados. Essa posição pode ser defendida, por exemplo, a partir da produção seminal de Anjos ${ }^{17}$, que no final dos anos 1980 trouxe para o campo da bioética o conceito de "mistanásia" para demonstrar como os conflitos de fim de vida atingem injustamente grupos mais pobres, que muitas vezes têm sua morte antecipada por falta de acesso a hospitais ou de condições básicas de saúde, como saneamento e alimentação.

As produções de Schramm ${ }^{20}$, por sua vez, chamam atenção para o processo de vulneração em saúde, ou seja, para mecanismos injustos que fragilizam grupos que não podem defender seus próprios interesses. Esse cenário levou o autor a desenvolver a chamada "bioética de proteção", abordagem que defende ações e políticas públicas prioritárias para resguardar os mais vulneráveis.

Na mesma linha, Garrafa e Porto ${ }^{21}$ propõem a "bioética de intervenção", enfatizando a responsabilidade do Estado e da sociedade civil pelos graves problemas sociais que geram desigualdades. Os autores desenvolveram abordagem específica do utilitarismo chamado de "utilitarismo orientador à equidade" para ser aplicado em contextos como o brasileiro e latino-americano, quando há uma maioria excluída e vulnerável que deve ser o sujeito preferencial das ações.

Recentemente, a partir do diálogo com a vertente social, Cunha ${ }^{22}$ fundamentou uma "bioética crítica", baseada no chamado "universalismo ético negativo", que identifica valor universal concreto para sustentar normas e ações ${ }^{23}$. Esse valor é o sofrimento comum (encontrado em todos os povos e locais do planeta) resultante da exploração econômica e ambiental relacionada à globalização, que acomete injustamente os grupos mais vulneráveis. Pouco depois, em 2018, Sanches, Mannes e Cunha ${ }^{24}$ elaboraram o conceito de "vulnerabilidade moral", chamando atenção para os processos que legitimam a exclusão, estigmatização e discriminação por meio da imposição de moralidade hegemônica, muitas vezes referendada por teorias científicas, econômicas, sociológicas ou teológicas.

Seguindo a perspectiva da bioética social latino-americana, os parâmetros para a tomada de decisão, tanto no contexto clínico quanto na definição de protocolos, normas e políticas públicas, devem priorizar grupos social e economicamente vulneráveis, historicamente excluídos, desprotegidos e explorados. Priorizar esses grupos em meio à maior crise sanitária dos últimos tempos seria não apenas reparar inaceitável injustiça histórica, mas também modo de apontar didaticamente para nova organização social pós-pandemia, mais justa e ética.

\section{Covid-19 no Brasil: parâmetros éticos}

Além de não agredir o ordenamento jurídico dos Estados, qualquer decisão ética em saúde deve atender os pressupostos dos direitos humanos consagrados em acordos internacionais e ser deliberada à luz da bioética. A Declaração Universal dos Direitos Humanos ${ }^{25}$ e a Declaração Universal sobre Bioética e Direitos Humanos ${ }^{26}$ consideram inaceitável qualquer tipo de discriminação. Na mesma linha, o Código de Ética Médica vigente no Brasil consagra em seus princípios fundamentais que a medicina é uma profissão a serviço da saúde do ser humano e da coletividade e será exercida sem discriminação de nenhuma natureza ${ }^{27}$. O ordenamento jurídico pátrio conta ainda com o Estatuto do Idoso, que assegura em seu artigo 15 a atenção integral à saúde do idoso, (...) para a prevenção, promoção, proteção e recuperação da saúde, incluindo a atenção especial às doenças que afetam preferencialmente os idosos ${ }^{28}$.

Com base nesses referenciais e nas correntes teóricas analisadas, apresentam-se a seguir contribuições da bioética para o enfrentamento dos conflitos gerados pela pandemia. Antes disso, no entanto, é importante destacar que a bioética considera pouco provável encontrar soluções consensuais para os conflitos morais persistentes na assistência em saúde. Portanto, a busca será por soluções que sejam as mais razoáveis e prudentes.

Obrigatoriamente, para o adequado cumprimento de um roteiro em bioética, há de se considerar fatos científicos (território da medicina baseada em evidências) e valores morais de todos os que protagonizam o processo deliberativo (território da subjetividade humana). Considerando esses condicionantes, fica claro que protocolos e consensos expedidos por associações de especialistas devem servir unicamente como elementos orientadores, nunca como critério único para deliberações clínicas. É fundamental ressaltar esse pressuposto, pois profissionais de saúde, sobretudo médicos, tendem a basear suas decisões apenas em evidências científicas, enfatizadas durante a formação. Outro elemento essencial é considerar cada caso clínico como evento único, que conta com variáveis nosológicas e biográficas específicas ${ }^{29}$.

Feitas essas considerações, apresentam-se alguns parâmetros para a tomada de decisão nesse momento de pandemia: 
1. Nunca raciocinar a partir de teorias que escalonem valor e dignidade da vida. Não há critério para definir que um humano valha mais ou menos que outro. Escolher pode ser necessário, mas resumir a decisão ao critério etário é reduzir a complexidade da situação e assumir postura ideológica em detrimento da reflexão ética.

2. Manter sempre no horizonte a busca da beneficência e o respeito à autonomia dos pacientes.

3. Afirmar, a cada dia, o propósito de cuidar bem de todos. Quando o cuidado for decisivo para manter a vida, respaldar-se no princípio da justiça, que implica o propósito de salvar o maior número possível de pessoas.

4. Quando a dramaticidade do cotidiano impõe escolhas, a decisão, baseada em critérios técnicos, deve visar salvar o maior número de pacientes. É necessário fugir de leituras reducionistas que induzem à deliberação a partir de critério único.

5. Nunca deixar de analisar criticamente as normas e seu contexto, buscando defender políticas públicas que promovam o direito à saúde e fortaleçam os sistemas de saúde, para que no futuro essa situação excepcional não se repita com a mesma gravidade.

6. Compreender que a responsabilidade pessoal tem limitações. Quando as condições estruturais da assistência em saúde inviabilizam salvar alguém, a perda de um paciente não pode ser vista como ato deliberado do profissional que presta assistência.

\section{Considerações finais}

A temática estudada não possibilita conclusão definitiva, dada a complexidade do processo decisório. No entanto, buscou-se evidenciar que os conflitos que surgem em tempos de pandemia podem ser amparados em perspectivas diversas de bioética. A abertura ao diálogo interdisciplinar, pautado pelo enriquecimento mútuo dos argumentos das diferentes vertentes, aponta para a necessidade de outras lógicas argumentativas que afastem a proposição simplista de que é preciso escolher entre a vida de paciente mais jovem ou mais velho.
Os parâmetros propostos não impõem receitas prontas e acabadas para os profissionais de saúde, pois, no campo ético, a responsabilidade é sempre daquele que realiza a ação, e não das diretrizes. No entanto, é papel da bioética apontar recomendações pertinentes ao contexto em questão. Nesse caso, é necessário destacar dois tipos de agente: o político, que pode implantar políticas e normas que impactam o sistema de saúde; e o "agente pessoal" - o profissional de saúde -, que precisa tomar decisões em contextos institucionais e estruturais definidos e limitados. Pode-se problematizar essa separação, pois certamente a ação política é marcada por decisões subjetivas, e a ação de indivíduos também é política, mas distinguir essas duas esferas ajuda a delimitar responsabilidades.

Quando o agente político atua, não tem diante de si a face dos pacientes impactados por suas decisões. Suas ações causam mortes ou preservam vidas, mas as consequências de suas escolhas passam por várias mediações e nem sempre são evidentes. O profissional de saúde, por outro lado, sofre diretamente com os efeitos de suas ações, pois o impacto sobre o paciente é imediato. Nesse sentido, a perspectiva da bioética social pode estabelecer parâmetros para apontar que o agente político deve ser responsabilizado quando não age a partir de evidências produzidas pelo melhor consenso das áreas do conhecimento em questão, quando normatiza protegendo determinados grupos sociais e quando implementa medidas que excluem dos serviços de saúde as populações mais vulneráveis.

A força do agente político é tão evidente que a covid-19 impacta de modo muito desigual diversos países e até regiões de um mesmo país. Rápida análise do impacto da pandemia em lugares diferentes já revela as consequências das decisões desse agente. Sua responsabilidade é evidente, e pode-se até mesmo indicar estatisticamente o impacto de determinada política no número de mortes. Nota-se, assim, a relevância da bioética, que tem potencial para denunciar signatários de políticas e normas obviamente discriminatórias e injustas. Assim, espera-se que agentes políticos sejam responsabilizados por medidas nefastas tomadas a partir de pressupostos excludentes e elitistas.

\section{Referências}

1. Wu Y, Chen C, Chan Y. The outbreak of covid-19: an overview. J Chin Med Assoc [Internet]. 2020 [acesso 29 jun 2020];83(3):217-20. DOI: 10.1097/JCMA.0000000000000270

2. Organização Mundial de Saúde declara pandemia do novo coronavírus. UNA-SUS [Internet]. 11 mar 2020 [acesso 18 jun 2020]. Disponível: https://bit.ly/3ky3qbS 
3. Tucídides. La peste en Atenas. In: de Riquer M, de Riquer B, organizadores. Reportajes de la historia: relatos de testigos directos sobre hechos ocurridos en 26 siglos. Barcelona: Acantilado; 2011. v. 1. p. 19-26.

4. Tucídides. Op. cit. p. 20. Tradução livre.

5. Gozalbes Cravioto E, García García I. La primera peste de los Antoninos (165-170): una epidemia en la Roma Imperial. Asclepio [Internet]. 2007 [acesso 10 ago 2020];59(1):7-22. p. 8. Tradução livre. Disponível: https://bit.ly/3kx1PDe

6. Boccaccio G. O decamerão. São Paulo: Livraria Martins; 1956. p. 29.

7. Muratori AL. Tratado del gobierno político de la peste, y del modo de precaverse de ella. Zaragoza: Francisco Magallon; 1801. p. 117.

8. Camus A. A peste. São Paulo: Record; 2017.

9. Saramago J. Ensaio sobre a cegueira. 2a ed. São Paulo: Companhia das Letras; 2020.

10. Beauchamp TL, Childress JF. Princípios de ética biomédica. São Paulo: Loyola; 2002.

11. Sgreccia E. Manual de bioética I: fundamentos e ética biomédica. São Paulo: Loyola; 1996.

12. Bentham J. Introduction to the principles of moral and legislation. Kittery: Franklin Classics Trade Press; 2018.

13. Mill JS. Utilitarismo. São Paulo: Martins Fontes; 2000.

14. Fortes PAC. Reflexão bioética sobre a priorização e o racionamento de cuidados de saúde: entre a utilidade social e a equidade. Cad Saúde Pública [Internet]. 2008 [acesso 18 jun 2020];24(3):696-701. DOI: 10.1590/S0102-311X2008000300024

15. Sariego JRA. Atención integral de la salud. In: Tealdi JC, organizador. Diccionario latinoamericano de bioética. Bogotá: Unesco; 2008. p. 80-3.

16. Cesari M, Proietti M. Covid-19 in Italy: ageism and decision making in a pandemic. J Am Med Dir Assoc [Internet]. 2020 [acesso 18 jun 2020];21(5):576-7. DOI: 10.1016/j.jamda.2020.03.025

17. Anjos MF. Eutanásia em chave de libertação. Bol Icaps. 1989;57:6.

18. Garrafa V. Dimensão da ética em saúde pública. São Paulo: Universidade de São Paulo; 1995.

19. Schramm FR. A terceira margem da saúde: a ética "natural". Hist Ciênc Saúde Manguinhos [Internet]. 1995 [acesso 18 jun 2020];1(2):54-68. DOI: 10.1590/S0104-59701995000100005

20. Schramm FR. A bioética da proteção em saúde pública. In: Fortes $P$, Zoboli $E$, organizadores. Bioética e saúde pública. São Paulo: Loyola; 2003. p. 71-84.

21. Garrafa V, Porto D. Intervention bioethics: a proposal for peripheral countries in a context of power and injustice. Bioethics [Internet]. 2003 [acesso 10 ago 2020];17(5-6):399-416. DOI: 10.1111/1467-8519.00356

22. Cunha TR. Bioética crítica, saúde global e a agenda do desenvolvimento [tese] [Internet]. Brasília: Universidade de Brasília; 2014 [acesso 29 jun 2020]. Disponível: https://bit.ly/2PDr5JJ

23. Cunha TR, Lorenzo C. Bioética global na perspectiva da bioética crítica. Rev. bioét. (Impr.) [Internet]. 2014 [acesso 29 jun 2020];22(1):116-25. DOI: 10.1590/S1983-80422014000100013

24. Sanches M, Mannes M, Cunha TR. Vulnerabilidade moral: leitura das exclusões no contexto da bioética. Rev. bioét. (Impr.) [Internet]. 2018 [acesso 29 jun 2020];26(1):39-46. DOI: $10.1590 / 1983-80422018261224$

25. Organização das Nações Unidas. Declaração universal dos direitos humanos [Internet]. Paris: ONU; 1948 [acesso 27 ago 2019]. Disponível: https://bit.ly/3dLdY3V

26. Organização das Nações Unidas para a Educação, a Ciência e a Cultura. Declaração universal sobre bioética e direitos humanos [Internet]. Paris: Unesco; 2005 [acesso 27 mar 2020]. Disponível: https://bit.ly/2Uy4H7G

27. Conselho Federal de Medicina. Resolução CFM no 2.217/2018. Aprova o Código de Ética Médica. Diário Oficial da União [Internet]. Brasília, p. 79, 10 nov 2018 [acesso 5 fev 2019]. Seção 1. Disponível: https://bit.ly/2WWsSyg

28. Brasil. Lei no 10.741 , de 10 de outubro de 2003. Dispõe sobre o Estatuto do Idoso e dá outras providências. Diário Oficial da União [Internet]. Brasília, 3 out 2003 [acesso 18 jun 2020]. Disponível: https://bit.ly/3gLqPE9

29. Gracia D. El papel de las metodologías en ética clínica. Madri: Universidad Complutense; 2009.

\section{Participação dos autores}

Os autores contribuíram igualmente para o artigo.

\section{Correspondência}

Mário Antônio Sanches - Rua 22 de Abril, 529, Centro CEP 83323-240. Pinhais/PR, Brasil.

Mário Antônio Sanches - Doutor - m.sanches@pucpr.br

(iD) 0000-0002-5794-2272

Thiago Rocha da Cunha - Doutor - rocha.thiago@pucpr.br

(iD) 0000-0002-6330-2714

Sergio Surugi de Siqueira - Doutor - sergio.siqueira@pucpr.br

(iD) 0000-0003-4344-6339

José Eduardo de Siqueira - Doutor - eduardo.jose@pucpr.br

(iD) $0000-0002-7513-1385$ 